"In this paper we suggest": changing patterns of disciplinary metadiscourse

\author{
Ken Hyland \& Fang (Kevin) Jiang
}

Corresponding author:

Prof Ken Hyland

Professor of Applied Linguistics in Education

School of Education and Lifelong Learning

University of East Anglia

Norwich Research Park

Norwich NR4 7TJ

United Kingdom

K.hyland@uea.ac.uk 


\section{"In this paper we suggest": changing patterns of disciplinary metadiscourse}

Synchrony and diachrony are complementary perspectives on language use but, with notable exceptions, research in academic and professional discourse has almost exclusively focused on the description and analysis of language rather than the historical processes that affect it over time. How disciplinary writing changes and develops, however, is important to our understanding of current practices; both in providing an awareness of how we got to where we are and in offering insights into the relationship between language and its contexts of use. Such insights are, of course, the lifeblood of ESP instruction. Authors such as Atkinson (1999), Banks (2008), Bazerman (1988), Valle (1999) and Salager-Meyer, (1999) have all made important contributions to this endeavour, revealing significant changes in the apparently frozen textual surfaces of (usually) scientific research articles. If not always theorizing the conditions and situations that may have promoted the changes in the text, these studies have reinforced our understanding that academic writing is not so much "natural" but very much a form of knowledge construction.

Our own interest in changes in professional research writing concerns recent developments in rhetorical practices and in academic interactions more specifically. We were initially moved to see if there was evidence for an often-heard claim that academic writing has become more informal in recent years (Hyland and Jiang, 2017), finding that this may be the case in the hard sciences, but the social sciences seemed to be heading in the opposite direction. This surprising result encouraged us to look for diachronic change in intersubjective positioning in greater detail, first exploring stance-making practices (Hyland \& Jiang, 2016a) and then reader engagement strategies (Hyland \& Jiang, 2016b). These studies show overlapping results: broadly that applied linguists and sociologist now present their research more impersonally and make less explicit effort to finesse readers, while electronic engineers and biologists are more visible in their texts and seek to connect with their audience more directly.

In the current manuscript we extend the diachronic research into academic writing to recent times and broaden our own line of work to examine interaction through the lens of metadiscourse. 
Metadiscourse is the commentary on a text made by its producer in the course of speaking or writing and has become one of the most productive ways of modelling interaction. Interaction is understood here as the writer's rhetorical awareness of the reader as a participant in the discourse, as someone who, through the choice of metadiscourse devices, can be engaged, guided and swayed by a text that is both comprehensible and persuasive. It focuses on those items which most overtly invoke the presence of the writer or reader in a text, organise propositional discourse, and display the writer's stance (Hyland, 2005).

Using the same corpus as the earlier studies, 360 articles of 2.2 million words compiled from the top journals in four disciplines, we explore whether, and to what extent, metadiscourse has changed in different disciplines over the past 50 years. This is an important extension to the previous investigations since metadiscourse, as seen below, comprises an important element of textual practice, comprising a set of rhetorical choices which not only help project the writer's perspective and engage readers, but also work to organize cohesive discourse. We believe this exploration contributes to the study of diachronic variation in academic writing and helps unpacks the impact of the significant changes which have occurred in publication and research practices in recent years. For teachers, a diachronic perspective on metadiscourse reinforces our awareness of the malleability of academic writing and its sensitivity to context as well as providing access to current practices for the creation and delivery of teaching materials.

\section{Metadiscourse and interactions in academic writing}

Academic knowledge is the outcome of a process of getting people to believe things. All reporting occurs within a disciplinary context and persuading readers to accept a particular observation as a worthwhile contribution involves careful decisions about how best to contextualise results and embed them in disciplinary argument, affiliation and agreement-making. Representations of reality have to be worked for as readers always have the option of refuting interpretations, which means writers must galvanize support for their claims and anticipate disagreement (e.g. Hyland, 2004). So, while research writing is a projection of a writer's voice, this is done with sensitivity to the expectations and views of a disciplinary audience. It is a place where writers and readers try to imagine each other's purposes and 
strategies and write or interpret a text in terms of these imaginations.

Academic texts therefore carry traces of these social interactions and analysts have sought to these interactions and reveal the rhetorical bases of persuasion. Metadiscourse has been a very productive tool in this regard and has a longish history itself, introduced by the structural linguist Zelig Harris (1959) and taken up in applied linguistics in the mid-1980s with the work of Vande Kopple (1985) and Crismore (1989). At the heart of the idea is the view that language not only refers to the world, concerned with exchanging information of various kinds, but also to itself: with material which helps readers to organise, interpret and evaluate what is being said. It is a way of looking at language use based on the fact that, as we speak or write, we monitor the possible responses of others, making decision about the kind of effects we are having on our listeners or readers, and adjusting our language to best achieve our purposes. It does this moreover, by focusing on lexico-grammatical items which are both searchable in a corpus, thus aggregating individual decisions to reveal community preferences, and which are eminently teachable. They therefore offer EAP instructors ways of helping students to examine the text they seek to engage in and using salient and high frequency items disciplinary experts find effective in their own texts. As a consequence, metadiscourse has been picked up and used by teachers across the globe (Hyland, 2017).

This does not mean the term, or the features it is used to embrace, is uncontested. Some researchers prefer to limit the term to explicit references to the text itself (e.g. Mauranen; 1993; Dahl, 2004), to illocutionary predicates (Beauvais, 1989) or to a relevance framework (Ifantidou, 2005). However, it is difficult to restrict authorial interventions to text organising or stance elements in any principled way. This is because an awareness of the reader not only involves assisting their grasp of cohesive connections but also the effect that their evaluation and assessments of material might be understood. In other words, the use of discourse to manage social relationships is inseparable from its role in managing the organisation of texts. With postmodern exceptions, a text communicates effectively only when the writer has correctly assessed both the reader's resources for interpreting it and his or her likely response to it and we cannot fully comprehend this process by arbitrarily excluding a whole area of relevant rhetorical activity. Academic writers therefore seek to balance claims for the significance 
of their research against the convictions and expectations of colleagues. Metadisccourse is one way in which they seek to anticipate readers' likely objections, background knowledge, rhetorical expectations and processing needs.

Thus, in this short extract from a research article (1) we see the authors intervening to review previously established information (in comparing Text 1 and Text 2), to frame the upcoming discussion (In the remainder of this section of the paper, features will be examined under four headings), offer evaluative commentary on the information presented (most striking difference, much more messy, what seem to be) and address readers directly through a direct question and a reference to 'us'.

(1) In comparing Text 1 and Text 2 the most striking difference is that the commercial text is very coherent, explicit and self-contained, whereas the authentic text is much more "messy". In the remainder of this section of the paper, we will examine in more detail some of the features which set these two texts apart. Why does one seem so coherent and the other rather disjointed? The answers tell us why the EAP course books are not able to prepare students adequately for authentic lecture listening. What seem to be the most important features will be examined under four headings...

The authors are therefore skilfully guiding readers' perceptions using devices which explicitly organise the propositional content and signal the writers' attitudes to both their material and their audience. These devices are metadiscoursal features.

\section{An interpersonal model of metadiscourse}

A widely used model of metadiscourse is that proposed by Hyland (2004; 2005; Hyland and Tse, 2004) which distinguishes interactive and interactional resources (terms adapted from Thompson, 2001). The former is concerned with ways of organising discourse and reflect the writer's assessment of what needs to be made explicit to guide what should be recovered from the text. The latter concern the writer's efforts to control the level of personality in a text and establish a suitable relationship to his or her data, arguments and audience, marking the degree of intimacy, the extent of reader involvement and the expression of attitude and commitments. These purposes, together with example realisations, are: 
Interactive resources allow the writer to manage the information flow to establish his or her preferred interpretations. They include:

- Transitions comprise an array of devices, mainly conjunctions, used to mark additive, contrastive, and consequential relations between main clauses (in addition / but / thus / however).

- Frame markers are references to text boundaries or text structure, including items used to sequence, to label text stages, to announce discourse goals and to indicate topic shifts (finally / to conclude / my purpose is).

- Endophoric markers make additional material salient to the reader in recovering the writer's intentions by referring to other parts of the text (noted above / see Fig / in section 2).

- Evidentials indicate the source of information which originates outside the current text, mainly consisting of citations (Smith argues) and explicit evidential markers (as according to).

- Code glosses signal the reworking of ideational information (e.g., for instance, in other words).

Interactional resources focus on the participants of the interaction and display the writer's persona and a tenor consistent with community norms. They include:

- Hedges withhold the writer's full commitment to a statement (might / perhaps / possible /about)

- Boosters express certainty and emphasise the force of propositions (in fact / definitely / it is clear)

- Attitude markers express the writer's attitude to propositions, conveying surprise, obligation, agreement, importance, and so on (unfortunately / I agree / surprisingly).

- Engagement markers explicitly address readers by focusing their attention or including them in the text through second person pronouns, imperatives, questions and asides. (consider/ note that) - Self-mentions explicit reference to authors $(I$, we, our, $m y$, etc.)

The identification of these features emerges from a long and distinguished engagement by linguists in the pragmatic and rhetorical features of discourse (e.g. Chafe \& Nichols, 1986; Nystrand, 1989; Crismore, 1989; etc.) and elaborated in the work of Hyland (2005; Hyland \& Tse, 2004). Essentially, the model suggests that metadiscourse is interpersonal in that it takes account of the reader's knowledge, textual experiences and processing needs and that it provides writers with an armoury of 
rhetorical appeals to achieve interactional goals. In sum, the model foregrounds the linguistic devices writers employ to shape their arguments to the needs and expectations of their target readers.

\section{Metadiscourse and discipline}

An orientation to the reader is crucial in research writing as writers must anticipate and respond to the potential negation of their arguments. This, in turn, involves making assessments of their readers likely knowledge and expectations. Metadiscourse demonstrates the workings of the author's recipient design filter, spelling out how he or she intends a message to be understood. Drawing attention to the text in this way reveals an awareness of the reader and therefore something of how the writer understands the community being addressed (Hyland, 2005; Hyland \& Tse, 2004). Metadiscourse thus suggests a familiarity with an audience and so connects texts with contexts. Because of this, it has been used to explore patterns of interaction, most commonly in an academic register, in different languages and genres.

Studies of academic metadiscourse date back to the early 1990s and have tended to focus on comparing texts in one language (almost always English) with those in another (e.g. Hu and Cao, 2011; Mur-Duenas, 2011) or Non-native English speakers writing academic texts in English (e.g. Hong and Cao, 2014; Li \& Wharton, 2012). These comparative studies tend to find that successful academic writing in English tends towards an Anglo-American rhetoric which projects a more readeroriented attitude, with more reader guidance and explicit authorial presence. Other studies have explored writing in English, particularly research articles, and often their introductions (e.g. Rubio, 2011 ) or abstracts (e.g. Gillaerts \& Ven de Velde, 2010). Comparisons across genres and disciplines are common. In one genre comparison, for example, Kawase (2015) found the different purposes and characteristics of the two genres mean that writers use far more metadiscourse in the article introductions than in the $\mathrm{PhD}$ theses they are based on, with less reference to other parts of the text and to authorial presence.

Cross-disciplinary metadiscourse studies have been particularly productive. Variations in the ways writers use metadiscourse have not only been found in research articles (e.g. Jiang \& Hyland, 2016; 
Cao \& Hu, 2014), but also in undergraduate essays (Noble, 2010), post graduate dissertations (Charles, 2006), academic book reviews (Tse \& Hyland, 2006), and university textbooks (Hyland, 1999). Thus, Bruce (2010), for example, found significant differences between the essays by students in sociology and English in the "complex variety of rhetorical purposes and associated textual resources that they draw upon" (p. 153). Such studies reveal considerable variations in academic persuasion and have helped illuminate the rhetorical and social distinctiveness of disciplines. This is because they point to the routine, almost automatic, use of conventions which are developed through participation in particular communities and which index a shared context for insiders.

Systematic analysis of these metadiscourse features shows how writers set out their ideas, take up positions and align themselves with their readers in a particular context. Only Gillaerts and Van de Velde's study (2010) takes a diachronic view, however, and they focused on just three features in abstracts of one discipline. Here we address this gap, focusing on high Impact Factor journals in contrasting disciplines.

\section{Corpus and method}

To trace changes in metadiscourse over the past 50 years we created three corpora taking research articles from the same five journals in four disciplines at three periods over the past 50 years: 1965, 1985 and 2015. The fact that journals come and go, that they undergo topic splitting and specialisation, and that they are replaced by new ones over time places some constraints on diachronic research, but we sought to select robust journals at the top of their respective fields (as defined by the Thompson-Reuters categories) with a long history.

The disciplines we selected were applied linguistics, sociology, electrical engineering and biology, representing both soft and hard sciences (e.g. Becher \& Trowler, 2001) to obtain a cross-section of academic practices. From each of these four fields we took six papers at random from each of the five journals which had achieved the top ranking according to their 5-year impact factor in 2015. The journals are listed in Appendix 1. Two journals, TESOL Quarterly and Foreign Language Annals, only began in 1967 and so papers were chosen from issues in that year. Single and co-authored papers 
were chosen in equal numbers. Overall, the corpus comprises 30 articles from each discipline from each year, 360 papers of 2.2 million words (see Table 1), showing a massive increase in the length of articles over the period:

Table 1: The diachronic corpus

\begin{tabular}{lcccc}
\hline Discipline & $\mathbf{1 9 6 5}$ & $\mathbf{1 9 8 5}$ & $\mathbf{2 0 1 5}$ & Overall \\
Applied linguistics & 110,832 & 144,859 & 237,452 & 493,143 \\
Biology & 244,706 & 263,465 & 237,998 & 746,169 \\
Engineering & 92,062 & 97,545, & 235,681 & 425,288 \\
Sociology & 149,788 & 196,232 & 262,203 & 608,223 \\
& & & & \\
Totals & 597,388 & 702,101 & 973,334 & $2,272,823$ \\
\hline
\end{tabular}

Using the concordance software Antconc (Anthony, 2011) we then searched each of the 12 subcorpora for the items in Hyland's (2005) list of most common metadiscourse words and phrases in academic writing. It should be noted that metadiscourse is essentially an open category to which writers are able to add new items according to the needs of the context, while insider opacity means that the analyst may never recover all intended metadiscoursal meanings. The focus must therefore be on explicit textual devices. So, while not exhaustive, these 500 items provide a basis for examining diachronic and disciplinary variations. It is also important to recognise that metadiscourse is often realised by signals which can stretch to clause or sentence length so that frequency counts do not convey the overall amount of metadiscourse in a corpus, but simply compare different patterns of occurrence of metadiscourse in corpora of unequal sizes.

One decision we made at this point was to omit both and and or from the counts of transitions. These are default options of marking conjunctive relations of addition and alternation rather than rhetorical strategies and produced thousands of examples. Biber et al (1999: 79) note that and and or are far more frequent in academic prose than in conversation, while but is least frequent in academic prose (1999, p. 81) where contrast is more commonly expressed by although, however, nevertheless and on the other hand. Our scan of a $10 \%$ sample of these three items agreed with this observation so we omitted and and or but not but.

We then manually checked the concordance lines containing every occurrence of these items to ensure 
that they were functioning as metadiscourse (according to the definitions above) and exclude extraneous examples. Both authors worked independently on a sample of cases and achieved an interrater agreement of $95 \%$ before resolving disagreements. This step helps avoid counting forms rather than forms acting in the service of rhetorical objectives. Having checked all instances to ensure they were performing metadiscoursal functions, we then normalised the results to 10,000 words to allow comparison across the corpora. Log likelihood tests were then used to determine statistical significances.

\section{Changing patterns of interaction: a quantitative overview}

Overall the 2015 corpus contained around 573 cases of metadiscourse per 10,000 words of text. Fig 1 shows this was a substantial increase of $85.2 \%$ since 1965 or 263 cases per article. This remains a significant increase of $11.5 \%$ (log likelihood $=300.63, p<0.001)$ even when adjusted for the large increase in the length of papers.

Figure 1 Change of interactive and interaction metadiscourse over time (per 10,000 words)

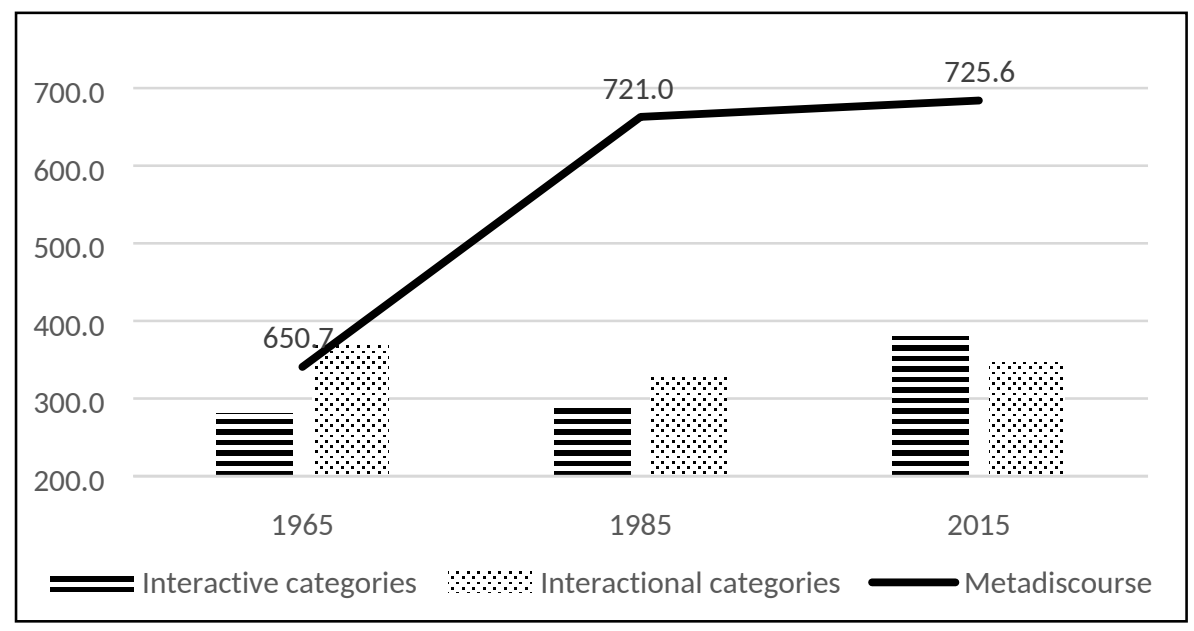

So interaction seems to have grown fairly substantially in academic writing in the past 50 years, but when we look more closely we find that this is entirely due to an increase in interactive forms. Thus there was a statistically significant increase in interactive features (log likelihood $=1092.70, p<$ $0.001)$ and a significant decrease in the interactional ones (log likelihood $=60.52, p<0.001)$ between 1965 and 2015. Table 2 presents the categories of metadiscourse and how their use has changed over this period, with writers using more interactive forms. Hedges and transitions are by far the most frequent devices in the corpus across all time periods. 
Table 2 Distribution of interactive and interactional features over time (per 10,000 words)

\begin{tabular}{llllllll}
\hline Interactive & $\mathbf{1 9 6 5}$ & $\mathbf{1 9 8 5}$ & $\mathbf{2 0 1 5}$ & Interactional & $\mathbf{1 9 6 5}$ & $\mathbf{1 9 8 5}$ & $\mathbf{2 0 1 5}$ \\
\hline Frame markers & 42.4 & 49.5 & 48.7 & Hedges & 155.9 & 143.3 & 138.3 \\
Transitions & 111.7 & 128.5 & 108.9 & Boosters & 86.2 & 65.6 & 67.4 \\
Evidentials & 72.1 & 88.5 & 142.2 & Attitude mkrs & 32.1 & 29.2 & 24.8 \\
Endophorics & 26.2 & 31.5 & 35.2 & Self-mention & 50.1 & 53.5 & 74.4 \\
Code glosses & 27.9 & 36.4 & 44.4 & Engagement mkrs & 46.1 & 44.4 & 40.3 \\
\hline Total & $\mathbf{2 8 0 . 3}$ & $\mathbf{3 3 8 . 1}$ & $\mathbf{3 7 9 . 4}$ & Total & $\mathbf{3 7 0 . 4}$ & $\mathbf{3 8 2 . 9}$ & $\mathbf{3 4 6 . 2}$ \\
\hline
\end{tabular}

These trends are perhaps surprising given the considerable attention interaction has attracted among analysts in recent years. Most unexpected is the decline in the more explicit interactional type which conveys the kind of stance and the strength of reader engagement the author wishes to project. While there is no 'faceless' writing, and all language choices represent rhetorical decisions that affect how readers react to a text, it is interesting to see fewer explicit authorial intrusions used to convey a professional 'take' on their material. Boosters (-21.8\%) and attitude markers (-22.7\%) showed the biggest falls, indicating changing preferences for strong authorial standpoints on issues, although there was greater personal presence with self-mentions increasing by nearly $50 \%$. Interactive resources, in contrast, have seen a significant increase since 1965, particularly in evidentials (up 97\%) and code glosses $(59 \%)$. The former are references to external sources and the increase documents the evercloser ties of research to the particular topic under discussion. Code glosses, on the other hand, clarify or rephrase statements or words, and their greater use perhaps recognises the growing complexity of scientific research or its increasing dissemination to less specialised audiences.

The overall increase in interactive features has been uniform across the four disciplines we studied, with particularly high increases in applied linguistics, where they have risen by $70 \%$, and engineering by $35 \%$. The decline in interactional items, however, is not so evenly distributed but indicates changing argument patterns in different disciplines. Table 3 shows there were considerable falls in the use of explicit stance features in applied linguistics and sociology over the period, with the decline in interactional features so substantial in applied linguistics that writers are now using less metadiscourse 
overall than they were in 1965. In contrast, biologists and engineers have adopted a more visible presence in their writing, especially in the last 30 years.

Table 3 Changes in metadiscourse categories by discipline (per 10,000 words)

\begin{tabular}{|l|ccc|ccc|ccc|ccc|}
\hline & \multicolumn{2}{|c|}{ Applied linguistics } & \multicolumn{3}{|c|}{ Sociology } & \multicolumn{3}{c|}{ Biology } & \multicolumn{3}{c|}{ Elec Engineering } \\
\hline Categories & $\mathbf{1 9 6 5}$ & $\mathbf{1 9 8 5}$ & $\mathbf{2 0 1 5}$ & $\mathbf{1 9 6 5}$ & $\mathbf{1 9 8 5}$ & $\mathbf{2 0 1 5}$ & $\mathbf{1 9 6 5}$ & $\mathbf{1 9 8 5}$ & $\mathbf{2 0 1 5}$ & $\mathbf{1 9 6 5}$ & $\mathbf{1 9 8 5}$ & $\mathbf{2 0 1 5}$ \\
\hline Interactive & 209.6 & 251.8 & 356.6 & 275.0 & 282.6 & 377.4 & 312.5 & 326.8 & 394.3 & 288.7 & 332.3 & 389.1 \\
Interactional & 506.4 & 418.3 & 333.0 & 437.8 & 353.9 & 360.8 & 280.1 & 254.8 & 308.4 & 337.1 & 351.7 & 381.6 \\
\hline Total & $\mathbf{7 1 6 . 0}$ & $\mathbf{6 7 0 . 1}$ & $\mathbf{6 8 9 . 6}$ & $\mathbf{7 1 2 . 8}$ & $\mathbf{6 3 6 . 5}$ & $\mathbf{7 3 8 . 2}$ & $\mathbf{5 9 2 . 6}$ & $\mathbf{5 8 1 . 6}$ & $\mathbf{7 0 2 . 7}$ & $\mathbf{6 2 5 . 8}$ & $\mathbf{6 8 4 . 0}$ & $\mathbf{7 7 0 . 7}$ \\
\hline
\end{tabular}

In the next two sections we explore these results in more detail, beginning with interactive features.

\section{Guiding readers: changes in interactive metadiscourse}

Interactive features seek to shape and constrain a text to better ensure that readers will recover the writer's interpretations and goals, organising the discourse with the assumed readers' needs in mind. In every discipline, these features display a steady increase, with particularly substantial rises in applied linguistics and electrical engineering. This points to their rhetorical importance in academic persuasion and indicates they are not merely text organising devices but mark writers' assessments of readers' expectations and knowledge. They are expressions of routine community practices: markers of discipline.

Table 4 shows that transitions and evidentials are by far the most frequent interactive devices in all four disciplines and that endophorics and code glosses have increased across the board. The frequencies of transition markers have held fairly steady across the years, although rising by $9 \%$ in applied linguistics, but the overall proportion of these items has declined dramatically. In fact, they have fallen from $40 \%$ of all interactive markers in 1965 to $28 \%$ in 2015 as evidentials have risen to make up $38 \%$ of devices.

Table 4 Changes in interactive metadiscourse by discipline (per 10,000 words) 


\begin{tabular}{|l|lll|lllllll|lll|l}
\hline & Applied linguistics & \multicolumn{3}{|c|}{ Sociology } & \multicolumn{3}{c|}{ Biology } & \multicolumn{2}{c|}{ Elec Engineering } \\
\hline Markers & $\mathbf{1 9 6 5}$ & $\mathbf{1 9 8 5}$ & $\mathbf{2 0 1 5}$ & $\mathbf{1 9 6 5}$ & $\mathbf{1 9 8 5}$ & $\mathbf{2 0 1 5}$ & $\mathbf{1 9 6 5}$ & $\mathbf{1 9 8 5}$ & $\mathbf{2 0 1 5}$ & $\mathbf{1 9 6 5}$ & $\mathbf{1 9 8 5}$ & $\mathbf{2 0 1 5}$ \\
\hline Transitions & 103.0 & 108.9 & 112.7 & 122.0 & 118.5 & 118.6 & 116.8 & 112.9 & 113.7 & 92.1 & 91.1 & 89.2 \\
\hline Frame mkrs & 41.6 & 41.0 & 37.6 & 49.2 & 43.4 & 42.0 & 27.1 & 27.5 & 33.2 & 73.3 & 84.1 & 83.1 \\
\hline Code glosses & 39.5 & 41.5 & 51.7 & 31.0 & 31.1 & 42.9 & 19.0 & 22.7 & 42.1 & 32.5 & 40.1 & 40.9 \\
\hline Endophorics & 16.5 & 17.9 & 23.5 & 11.3 & 13.0 & 18.1 & 28.2 & 29.4 & 32.0 & 57.0 & 63.4 & 69.1 \\
\hline Evidentials & 9.0 & 42.5 & 131.1 & 61.5 & 76.6 & 155.8 & 121.4 & 134.3 & 173.3 & 33.8 & 53.6 & 106.8 \\
\hline Total & $\mathbf{2 0 9 . 6}$ & $\mathbf{2 5 1 . 8}$ & $\mathbf{3 5 6 . 6}$ & $\mathbf{2 7 5 . 0}$ & $\mathbf{2 8 2 . 6}$ & $\mathbf{3 7 7 . 4}$ & $\mathbf{3 1 2 . 5}$ & $\mathbf{3 2 6 . 8}$ & $\mathbf{3 9 4 . 3}$ & $\mathbf{2 8 8 . 7}$ & $\mathbf{3 3 2 . 3}$ & $\mathbf{3 8 9 . 1}$ \\
\hline
\end{tabular}

Transition markers are conjunctions and adverbial phrases which signal logical relations in the writer's thinking and help readers interpret connections between clauses and so steps in an argument. Having eliminated 'and' and 'or' from these counts due to their routine automaticity as default connectors, we noted that also replaced but as the most common transition marker in recent years, with however, since and because consistently filling the next positions, indicating the most common means of expressing additive, contrastive and consequence relations. The positional flexibility of but makes it a popular coordinator and it is increasing as a sentence initial contrastive marker, although however is some 6 times more common in this position, as initial but still retains something of an informal flavour (Hyland \& Jiang, 2017).

(2) But the view has not entirely faded from the scene. (Soc)

(3) But further depletion of the oxygen in the surrounding fluid, or treatment of the preparation with cyanide, caused contraction to stop. (Bio)

In addition, and significantly, transitions are increasingly used to explicitly mark consequential relations, clearly signalling the implications of a finding or statement and drawing conclusions from it for the reader:

(4) As a result, INCORA runs the risk of becoming just another agency for colonization for which Colombia and other Latin American nations have had 
sad historical experiences.

(Soc)

(5) Hence, a HK-system is in equilibrium if and only if no two clusters are within unit distance of each other.

These choices correspond to a larger trend towards greater explicitness and, as we will argue below, a rhetoric which is more geared towards regulating reader interpretation and overt persuasion.

Frame markers, used to label larger up-coming segments of text, shift in direction or the sequencing of material, have declined in the soft knowledge fields and increased in the hard sciences, with electronic engineers being the heaviest users of these forms. The increase in engineering may in part be because of the growth in the average length of its research papers, rising over 2.5 times in 50 years, as longer papers require more explicit structuring:

(6) Our purpose here is to show that electromagnetic software cannot only be applied for analysis in the last step before the realization of the device, but can also ...

(7) This section has three sub-sections. First, the necessary notations are presented. Then the branching scheme is described. In the final sub-section the algorithm is provided.

The $22 \%$ increase in frame markers in biology was also due to their use in more overtly ordering an argument, often acting as more explicit additive relations:

(8) We pursue this idea with four general messages in mind. First, a complete description of the hierarchy will aid biological understanding of phenotypic variance. Second, hierarchical descriptions of phenotypic variance highlight the fact that patterns at one level in the hierarchy ... Third, another improvement to understanding arises because being explicit about hierarchical variance and the patterns ... Finally, and perhaps most importantly, fully partitioning variance reveals patterns that demand explanation...

Such overt marking of sequence obviously assists comprehension and processing and perhaps suggest the writers' assumption that their readership may include those with little background knowledge in the method they have used.

Both code glosses and endophoric markers have increased across all disciplines, mainly in the past 30 years, as texts appear to be increasingly explicit in elaborating concepts, spelling out connections 
between ideas, and clarifying associations between text entities. We can see the effect of these options here, where the addition of code glosses ( $9 \& 10)$ and endophrics ( $11 \& 12)$, bring greater clarity to the exposition:

(9) The teacher divided the 30 hours of class instruction as follows: $20 \%$ administrative tasks (e.g.. test and quiz administration, reading record completion, homework review) and $80 \%$ small-group or pair activities.

(10) These people are often active in social change organisations, but their theories do not provide intellectual support for their actions, or put differently, do not explain their practices to them.

(Soc)

(11) In the latter case the concentration profile of solids in the vessel was also measured, using the technique described earlier.

(12) For more information, see Table 2, and see Fig. 2 for representative data. (EE)

Code glosses elaborate on the meaning of a clause or item by further specifying, qualifying, describing or extending it, thereby clarifying the writer's communicative purpose (e.g. Hyland, 2007). The exemplification in (9) and the reformulation in (10) offer on-line elucidation to assist the reader in following the writer's argument, making the ideas immediately accessible to them. Code glosses have risen the most in biology (by 122\%), although this was a discipline which seems to make little use of then in the past and the increase brings frequencies more in line with the comparison disciplines. Endophoric markers, by referring the reader to another part of the current text (11) or to supporting data (12) make material salient which is necessary for the reader to recover the writer's preferred interpretations. The more quantitative disciplines make the most use of this feature, often pointing to tables, figures or other ways of presenting numerical data outside of the linear verbal exposition. The increase in these features perhaps indicates greater awareness of readers' processing needs, or at least greater care in constructing arguments. This augmented support, in turn, may reflect the emergence of new audiences for academic research who are not specialists in the area and so a change in the rhetorical conventions required to accommodate it.

The most dramatic change in the use of interactive features over this period is the huge growth in evidentials, which have more than doubled per 10,000 words to comprise $37 \%$ of all features ( $\log$ 
likelihood $=1645.56, p<0.001$ ). Evidentials point to sources of information outside the current text, either through citation (13) or an evidential marker (14).

(13) Bassett and Moss (2004) found that women preferred high and moderate risk takers as long-term mates over low risk takers...

(14) According to the symbolic politics framework, politicians promote antiimmigrant laws by making emotional appeals ...

Biology (up 43\%), sociology (153\%) and electrical engineering (216\%) have all seen massive rises, but the $1357 \%$ increase in applied linguistics is extraordinary. This increase, mainly driven by the massive growth of citation, is from an extremely low base, reflecting a time when the field was in in its infancy and lacking the substantial stock of citable sources it has now with nearly 600 journals listed on the SCImago rankings. All disciplines, however, have seen a shift to electronic publishing and the greater availability of material which can be easily accessed online, but more importantly, they have all seen an ever-growing body of literature to draw on and an ever-greater imperative to do so. Relating a study to previous work in order to establish the relevance and significance of the current work is now an essential part of building a context for research, particularly in the more discursive fields, as arguments have become increasing embedded in the conversations of the discipline.

We also observed a general shift in the form that evidentials take, with a growing preference away from summarising information from a single source to generalising from several sources, again, perhaps related to the growth of the research literature and the additional material to acknowledge, with introductions and discussions accounting for most references as citationological studies demonstrate (e.g. Bertin et al, 2016). Academic partiality for non-integral forms, where the cited authors occur in parenthesis to emphasise the actions of research rather than the researchers themselves, is also strengthening. Examples such as (15) and (16) have increased by over a third during the last 50 years so that integral patterns like (17) and (18) now represent only $15 \%$ of all citations in these four fields. 
(15) In this context, control-based approaches are increasingly being used in synthetic biology (Ang et al., 2010, LeDuc et al., 2011, Menolascina et al., 2011 and Yang et al., 2011).

(16) Depletion of aurora B kinase, which over-stabilises kMT attachments causes errors in chromosome alignment and segregation [7], [27], [30], [34], [35]. (Bio)

(17) According to Reveil (57) the primary event may be only a labile tendency to pair with another primary event.

(18) However, as Gleason (1965) points out: The focus of attention for the European grammarians has always been strongly on the details...

Overall then, interactive features show a statistically significant increase since 1965 with evidentials nearly doubling and code glosses also increasing markedly. Evidentials, in fact, was the category that rose the most in all fields except biology, where it was the third, while endophorics and code glosses increased in all fields. Across the board, then, we see writers seeking to enhance the cohesion and explicitness of their arguments in order to make their ideas more transparent and their texts more persuasive to an audience which increasingly includes those outside of their specialist area (Trowler et al, 2012).

\section{Authorial intrusion: changes in interactional metadiscourse}

In contrast to the rise in interactive features, interactional resources have seen a $6.5 \%$ drop (per 10,000 words) with devices in all categories except self-mention declining over 50 years. Self-mention on the other hand, where writers refer to themselves in the text, have increased by almost $50 \%$ and now represent a significant aspect of rhetorical persuasion in academic writing and a key way in which professional authors gain credit for their research claims (Hyland, 2004). Once again, the trends aren't uniform across disciplines and while applied linguistics and sociology have seen substantial declines overall, with falls in all categories in applied linguistics, biology and electrical engineering show modest but significant increases overall and in most categories. Table 6 details the movement of different features over the period in each discipline. 
Table 6 Changes in interactional metadiscourse by discipline (per 10,000 words)

\begin{tabular}{|c|c|c|c|c|c|c|c|c|c|c|c|c|}
\hline & \multicolumn{3}{|c|}{ Applied linguistics } & \multicolumn{3}{|c|}{ Sociology } & \multicolumn{3}{|c|}{ Biology } & \multicolumn{3}{|c|}{ Elec Engineering } \\
\hline Markers & 1965 & 1985 & 2015 & 1965 & 1985 & 2015 & 1965 & 1985 & 2015 & 1965 & 1985 & 2015 \\
\hline Hedges & 201.1 & 169.4 & 128.6 & 187.8 & 148.2 & 148.7 & 130.2 & 132.9 & 148.4 & 117.5 & 122.5 & 126.4 \\
\hline Boosters & 107.7 & 79.7 & 67.0 & 88.8 & 62.7 & 57.3 & 76.3 & 51.9 & 51.7 & 82.6 & 87.3 & 95.0 \\
\hline Self-mention & 94.0 & 87.8 & 68.4 & 65.3 & 67.1 & 89.9 & 19.8 & 20.2 & 52.1 & 52.8 & 65.1 & 85.8 \\
\hline Engagement & 54.4 & 43.0 & 37.8 & 55.2 & 44.9 & 36.9 & 25.9 & 26.2 & 28.3 & 50.6 & 55.0 & 55.3 \\
\hline Attitude mkrs & 42.3 & 38.5 & 31.2 & 35.7 & 32.0 & 28.0 & 27.9 & 24.3 & 27.2 & 9.5 & 8.5 & 16.4 \\
\hline Total & 506.4 & 418.3 & 333.0 & 437.8 & 353.9 & 360.8 & 280.1 & 254.8 & 308.4 & 337.1 & 351.7 & 381.6 \\
\hline
\end{tabular}

As mentioned above, boosters and attitude markers have shown the steepest decline over the last 50

years, and these are perhaps the most explicit indicators of the writer's authorial positioning,

conveying commitment and affective evaluations towards the material under discussion. Admittedly, attitude markers fell from a much smaller base, as the expression of affect is relatively infrequent in academic research writing (Biber et al, 1999) and tends to be implicitly invoked rather than openly inscribed. But because they are something of a marked choice they create greater impact when they do occur, expressing strong positive or negative judgements:

(19) Burton Blatt's extraordinary indictments of the institutional abuse of people with all levels of defined cognitive disability (Soc, 2015)

(20) This was an unexpected result and provides compelling evidence for the importance of deltas based on their size alone...

(Bio, 2015)

The most dramatic falls in the expression of affect have been in the soft knowledge fields with frequencies declining by $26 \%$ in applied linguistics and by $22 \%$ in sociology (normed to 10,000 words), suggesting that writers in sociology and applied linguistics are now taking a more objective, less personal stance towards their material. One reviewer of this paper notes that in the 1980s in applied linguistics there was often a single review and no expectation for a second round, nor was 
there the insistence that authors explain how they had responded to the reviewers' line-item comments. We are happy to agree that, together with the growth of multiple authorship, the advice of reviewers to remove an evaluative modifier may have "suppressed individual irrational exuberances".

The minimally exuberant important and restrictive even, while declining in numbers, have remained the most popular forms of affect across all four fields, enabling writers to present a positive evaluation which simultaneously aligns their stance with community-recognized assessments of value:

(21) An understanding of lay social actors' normative beliefs should be an important area of investigation for social scientists.

(Soc, 2015)

(22) Changing the threshold voltage dynamically then allows one to improve the threshold voltage of the device, even as the transistor has low standby current.

(EE, 2015)

Thus in (21) the writer takes a stance which explicitly positions him centrally with the knowledge of informed peers while (22) conveys a clear attitude by highlighting the relative unexpectedness of the result, comparing what is claimed against the assumed shared understandings of community readers.

Boosters also registered a substantial fall, particularly as expressed by modals like must and cognitive verbs such as recognise, believe and know, being replaced by show, demonstrate and find. This change represents an important shift from commitments expressed as personal beliefs (23) towards those which seek to convey more objective, data-supported assurances (Hyland \& Jiang, 2016a) (24):

(23) That, I believe, must be sought in an unhappy confusion in the minds of the teachers of composition.

(24) This analysis demonstrates the importance of using age-appropriate norms lists in the study of WA stereotypy. (AL, 2015) Boosters have declined most obviously in both soft knowledge disciplines and also shown a trend towards more verbal uses. The most common form in 1965 and 1985 in both applied linguistics and sociology was must, the main modal of inferential certainty, but this had disappeared from the top 20 by 2015, perhaps indicating the growing risk of presenting definitive judgements in a metrics-driven climate of greater competition as more researchers look for more productive topics in more journals. 
Although both attitude markers and boosters have fallen in three of the four disciplines studied, engineers have actually increase their use of these features; in fact, they have gradually increased their use of all interactional metadiscourse categories. Attitude markers, for instance, have risen by $73 \%$ in electrical engineering over the period and boosters by $15 \%$. Engineering, however, shares a small increase in hedges and engagement markers with biology and, while neither rise is substantial, the contrast with the soft knowledge fields is remarkable. Hedges are often a judicious option for writers as they allow them to mark their claims as provisional and subject to current objections and future revisions. By toning down the certainty of statements authors are able to more carefully align their novel assertions with the contemporary thinking of a disciplinary audience and position their claims in a more nuanced way. In these examples, for instance, we can see authors taking a stance which seeks to involve readers in their ratification of claims:

(25) In some cases, it may be better to tailor loss functions individually to each data set, and use norms other than Frobenius [8], [153].

(26) By several indicators, ratio dependence would appear to have the upper hand in the controversy over its usefulness.

(Bio, 2015)

Thus, calculating the conviction it seems wise to invest a claim with often depends on what readers in the field are likely to accept, so the decline in their use in applied linguistics, by $36 \%$, and in sociology by, $21 \%$, signals a change in the way writers perceive their readers and the appropriate degree of certainty they might feel comfortable with. In this regard, fewer hedges (and fewer boosters) indicate a more measured epistemic stance and a more circumspect approach to authorial intrusion than in the past. This may plausibly be related to what has been perceived by some as an increasing scientism in the social sciences with a more hard science orientation in their dominant methods and approaches (e.g. Glynos \& Howarth, 2007). In applied linguistics there has long been a debate around what constitutes legitimate disciplinary knowledge at the same time as the development of technologies which permit the quantitative support for findings and more precise measurement of data.

Interestingly, may and would remain the most common hedges in both social science disciplines but their combined frequencies fell by almost 50\% (per 10,000 words) over the period and the other modal 
hedges also declined. May, would, should, could and might represented $40 \%$ of all hedges in sociology and 48\% in applied linguistics in 1965 and 34\% and 34\% respectively in 2015, while suggest and likely were the only forms to become more common among the most frequent hedges. Thus there is both a decline in hedging and in forms which convey assumption (should and ought), possibilities (may, might and could) and hypotheticality (would). Instead, authors seem to be using hedges to make more speculative interpretations, drawing on the uncertainty in human evaluation rather than of the reliability of logical deduction or the vagaries of observational data:

(27) One can, of course, speculate about what might likely be causing the difficulty which in each case generates the repair initiation.

$(\mathrm{AL}, 2015)$

(28) At the heart of the normalisation thesis, we would suggest, is a confusion between normalcy and frequency.

(Soc, 2015)

The category of engagement markers has similarly risen slightly in the hard sciences and declined in the discursive soft fields. These enable writers to explicitly step into the text to focus readers on a particular aspect of the data or argument and guide their interpretations. These functions are accomplished by a range of features which have not demonstrated uniform change. Asides and explicit references to shared knowledge (signalled by forms such as of course and parentheses) have fallen steadily since 1965 in all four disciplines, perhaps indicating less confidence in what can be reliably called up as shared or the common knowledge which can be referred to with an aside. As we have noted elsewhere (Hyland \& Jiang, 2016b), this may be in response to changing contexts where interdisciplinary research and the need to talk to external funders, commercial sponsors and other non-specialist outsiders is becoming more important.

Other features have not behaved so neatly. Questions and directives have remained fairly stable except in biology, where questions have more than doubled, although they remain relatively infrequent, and electrical engineers have substantially increased their use of directives and reference to readers through use of inclusive we, especially between 1965 and 1985.

(29) We should note that the constant 48 in the exponent above is an upper bound. (EE)

(30) From this we easily see that $\mathrm{w}_{\mathrm{k}} *=1$ and all other $\mathrm{w}_{\mathrm{j}}=0$. 
The reason for the $65 \%$ increase in inclusive we by engineers is unclear, but we cannot rule out the pressure authors are under to rhetorically sell their knowledge to those outside their specialism and especially to the wider commercial world which funds much of its research. More interventionist engagement strategies, which explicitly pull readers along towards particular viewpoints, may therefore help compensate for a less certain ability to rely on the persuasive efficacy of in-group understandings of methods, theories and the significance of findings.

Finally, disciplines also differ in how their use of self-mention has changed, although applied linguists have become less overtly 'present' in their texts, frequencies for biology $(+163 \%)$, electrical engineering $(+63 \%)$ and sociology $(+38 \%)$ have all increased substantially. The use or avoidance of self-mention allows writers to be more or less visible in their texts, stepping in to explicitly signal their presence and take responsibility for claims and actions and credit for their interpretations. In the sciences writers have typically downplayed their personal role to highlight the phenomena under study, the replicability of research activities, and the generality of findings, circumventing first person to subtly convey an empiricist position where research outcomes do not depend on authorial intrusion. This increase in electrical engineering and biology is therefore surprising, although it is mainly confined to plural forms which allow authors to create more distance between themselves and their reporting than first person and so temper a more invasive stance, as these examples indicate:

(31) Our purpose here is to extend the capabilities of the fuzzy systems modeling technology by allowing a wider class of input information.

(EE, 2015)

(32) Here, we address the issue of temporal coding in dACC. $\underline{\text { We use recordings }}$ from monkeys engaged in a trial-and-error learning task [29].

The electrical engineering articles in our corpus, in fact, now have over 75\% more exclusive we pronouns than biology and sociology and twice as many as applied linguistics. One reason for this trend towards greater authorial presence in the hard knowledge fields may be the need for a more visible presence to ensure that their contributions do not go unnoticed by university human resource panels where applications for jobs, tenure and promotion are judged. Self-mention projects a more 
personal stance and signals an overt authorial role in interpretations of data and for claims of novelty, as in these examples:

(33) In this work we develop a theory of system approximation for timed systems by quantifying the timing differences between corresponding system events.

(34) We emphasize the need for probabilistic models which includes prior distributions in order to deal with the issues arising from ...

Such explicit authorial involvement may be an attempt to show clearly what the researchers have done to garner recognition and professional credit for their work.

Sociologists have also increased their use of self-mention but this is a more explicitly interpretative and less abstract discipline, where writers often need to craft a convincing argument without the support of exact laboratory methods. Taking a credible personal stance is part of this rhetorical presentation of reasoning. We might expect a similar increase in applied linguistics but instead see a $27 \%$ decline, indicating a shift towards a more 'author evacuated' style of argument we have noticed in the other interactional features discussed above. It should be noticed, however, that applied linguistics starts this period from a very high base and that in 1965 it was a young discipline with an undeveloped literature and a greater focus on personal accounts of language teaching. The increase in empirically-oriented studies, the broadening of the discipline to embrace a wider array of topics, and the massive growth of a literature which supports its academic endeavours have all contributed to massive changes in how claims are argued and accepted.

There has also been the influence on rhetorical practices of the growing number of second language writers schooled in the eliminating explicit agency from their academic writing (e.g. Hyland, 2012). Whatever the reason for this, and there may be several, the more ego-centric stance common 50 years ago in this field has been supplanted with a more collectivist one.

\section{Conclusions}

This study has sought to identify changes in patterns of disciplinary interaction over the past 50 years through the study of metadiscourse. The most obvious finding has been the divergent directions taken 
by the main sub-categories, with a significant increase in interactive features and a significant decrease in the interactional ones. Thus, writers are now using more features to guide readers through more explicitly cohesive texts and fewer to take a personal stance and engage directly with readers.

Obviously, our sample cannot represent overall diachronic changes in academic writing, so the more important findings are the divergences between disciplines, particularly within interactional forms. The use of metadiscourse is closely related to the social contexts it helps construct so it is not surprising to find variations across the disciplines we have studied. What is surprising, however, is that while there is a general trend towards more reader guidance in all fields, almost all interactional features have shown a marked decline in the discursive soft knowledge fields and a substantial increase in the science subjects. While the frequencies of some features are small, thus exaggerating percentage changes, there does seem to have been a rhetorical shift in argumentation patterns in academic writing towards a greater awareness of readers.

While we might hesitate to categorically account for these results, the changing and more diverse nature of disciplines, the influence of external funders and commercial sponsors, and the ever-closer connection between professional recognition and career advancement in an extremely competitive publication marketplace cannot be excluded. Further work might further elucidate these conjectures: similar studies of more disciplines could help validate our findings and indicate how far we can generalise them; text interviews with subject specialists could offer corroboration of our speculative claims linking discoursal and social changes; and collaborative work with historians and sociologists of science could supplement corpus research with the investigative techniques and insights of those more intimately involved in the study of the political, institutional and economic forces which shape modern science.

We should also note here that while we have foregrounded disciplines as significant sources of institutional influence on communicative practices in this paper, we are aware of arguments concerning the dwindling significance of disciplinary boundaries in the $21^{\text {st }}$ century and the importance of local ideologies (e.g. Manathunga \& Brew, 2012), of the interdisciplinary imperatives (Land, 2012) and of digital technologies (Oliver, 2012) on research work. However, 
like Trowler et al (2012: 246) we "acknowledge that disciplines have 'real' epistemological characteristics, that knowledge structures do condition practices in quite real ways". Applied linguistics is not electrical engineering and that fact has real consequences for those working in those fields. The training and acculturation involved in becoming a professional scholar largely involves acquiring knowledge in a specialised field, so that the disciplines are not just sources of knowledge but the foundations of a professional identity and the bases for shared communicative practices (Hyland, 2012). Our study shows members of different disciplines represent themselves and see their readers in quite different ways. What assistance they assume readers will need in making connections between ideas, how they anticipate reactions to their arguments, and how they should project themselves into their texts is, to some extent at least, indexed in their metadiscourse choices.

Disciplines may be diffuse structures with unclear boundaries, but they are at the interface of academic decision-making and institutional constraints and research papers are where individual beliefs and community expectations meet to reveal their everyday, commonplace workings. Writers have to make assumptions about their readers informed by an understanding of both discipline and genre and both change over time. This is why a sensitivity to diachronic change is valuable to writers. Advanced students, especially those taking ERPP courses, are studying academic writing as a specialised form of communication and the abstract, technical and metaphorical nature of these texts can blind students to their relativity: that, like other discourses, research texts are artefacts which represent a variety of practices appropriate for particular times, places, participants, and purposes. This is not to say that engineers and biologists need become historians to write successfully, but simply that it provides them with an understanding that literacy varies with context and cannot be distilled down to a set of cognitive or technical abilities. Advanced academic literacy presupposes control of disciplinary practices, and an awareness of diachronic change reinforces students' control to the cultural and linguistic resources necessary for them to engage critically with texts. 
In sum, academics write as members of disciplinary communities and publications represent their decisions about how best to present their work, their readers and themselves. For ESP practitioners, metadiscourse offers a coherent and principled means of analysing these rhetorical preferences. Tracking changes over time helps to show how these personal and collective imperatives have altered, indicating shifting conventions in response to major changes in the nature of publishing, the expansion of audiences, institutional measurement imperatives and research practices which favour increasing co-authorship.

\section{References}

Anthony, L. (2011). AntConc 3.4.3. http://www.laurenceanthony.net/software.html

Atkinson, D. (1999). Scientific discourse in sociohistorical context: The philosophical transactions of the royal society of london, 1675-1975. Mahwah, NJ: Lawrence Erlbaum Associates.

Banks, D. (2008). The development of scientific writing: Linguistic features and historical context. London: Equinox.

Bazerman, C. (1988). Shaping written knowledge: The genre and activity of the experimental article in science. Madison: University of Wisconsin Press Madison.

Beauvais, P. (1989). A speech-act theory of metadiscourse. Written Communication, 61, 11-30.

Becher, T. \& Trowler (2001). Academic tribes and territories: intellectual inquiry and the cultures of disciplines $2^{\text {nd }}$ ed. Milton Keynes, SRHE/Open University Press.

Bertin, M., Atanassova, I., Gingras, Y., \& Larivière, V. (2016). The invariant distribution of references in scientific articles. Journal of the Association for Information Science and Technology, 67(1), $164-177$.

Biber, D., Johansson, S., Leech, G., Conrad, S., \& Finegan, E. (1999). Longman grammar of spoken and written English. Harlow: Longman.

Bruce, I (2010). Textual and discoursal resources used in the essay genre in sociology and English. Journal of English for Academic Purposes 9 (3): 153-166

Cao, F., \& Hu, G. (2014). Interactive metadiscourse in research articles: A comparative study of paradigmatic and disciplinary influences. Journal of Pragmatics, 66, 15-31. 
Chafe, W., \& Nichols, J. (eds). (1986). Evidentiality: The linguistic coding of epistemology. Advances in Discourse Processes 20. Norwood, NJ: Ablex

Charles, M. (2006) 'The construction of stance in reporting clauses: a cross-disciplinary study of theses', Applied Linguistics, 27, 492-518.

Crismore, A. (1989). Talking with readers: Metadiscourse as rhetorical act._New York: Peter Lang.

Dahl, T. (2004). Textual metadiscourse in research articles: a marker of national culture or of academic discipline? Journal of Pragmatics. 36 (10): 1807-1825.

Gillaerts, P., Van de Velde, F. (2010). Interactional metadiscourse in research article abstracts. Journal of English for Academic Purposes 9 (2), pp. 128-139

Glynos, J. \& Howarth, D. (2007). Logics of critical explanation in social political theory. London: Routledge.

Harris, Z. (1959). The Transformational Model of Language Structure. Anthropological Linguistics 1 (1): $27-29$

Hong, HQ \& Cao, F. (2014) Interactional metadiscourse in young EFL learner writing A corpusbased study. International Journal of corpus linguistics. 19 (2): 201-224

Hu, G., and Cao, F. (2011). Hedging and boosting in abstracts of applied linguistics articles: A comparative study of English- and Chinese-medium journals. Journal of Pragmatics, 43, 27952809.

Hyland, K. (1999). Talking to students: metadiscourse in introductory textbooks. English for Specific Purposes._18 (1): 3-26.

Hyland, K. (2004). Disciplinary discourses: social interactions in academic writing. Ann Arbor: University of Michigan Press.

Hyland, K. (2005). Metadiscourse. London: Continuum

Hyland, K. (2007). Applying a gloss: Exemplifying and reformulating in academic discourse. Applied Linguistics 28 (2), pp. 266-285

Hyland, K. (2012). Disciplinary identities: Individuality and community in academic discourse. Cambridge: Cambridge University Press.

Hyland, K. (2017) Metadiscourse: what is it and where is it going? Journal of Pragmatics. Vol 113: 16-29 
Hyland, K., \& Jiang, F. K. (2016a). Change of attitude? A diachronic study of stance. Written Communication, 33(3), 251-274.

Hyland, K., \& Jiang, F. K. (2016b). "We must conclude that...”: A diachronic study of academic engagement. Journal of English for Academic Purposes, 24, 29-42.

Hyland, K., \& Jiang, F. K. (2017). Is academic writing becoming more informal? English for Specific Purposes, 45, 40-51.

Hyland, K., \& Tse, P. (2004). Metadiscourse in scholastic writing: a reappraisal. Applied Linguistics, 25(2), 156-177.

Ifantidou, E. (2005). The semantics and pragmatics of metadiscourse. Journal of Pragmatics. 37 (9). $1325-1353$

Jiang, FK \& Hyland, K. (2016). Nouns and Academic Interactions: A Neglected Feature of Metadiscourse. Applied linguistics. 10.1093/applin/amw023

Kawase, T. (2015). Metadiscourse in the introductions of $\mathrm{PhD}$ theses and research articles Journal of English for Academic Purposes. 20: 114-124

Land, R. (2012) Crossing Tribal Boundaries: Interdisciplinarity as a Threshold Concept. In Trowler et al. pp 175-185.

Li, T., \& Wharton, S. (2012). Metadiscourse repertoire of L1 Mandarin undergraduates writing in English: A cross-contextual, cross-disciplinary study. Journal of English for Academic Purposes, $11(4), 345-356$.

Manathunga, C. \& Brew, A. (2012), Beyond tribes and territories: new metaphors for new times. In Trowler, et al (eds.). pp 44-56.

Mauranen, A. (1993). Cultural differences in academic rhetoric. Frankfort: Peter Lang.

Mur Dueñas, P. (2011). “An intercultural analysis of metadiscourse features in research articles written in English and in Spanish". Journal of Pragmatics. 43 (12)" 3068-79.

Noble, W. (2010). Understanding Metadiscoursal Use: Lessons from a 'Local' Corpus of Learner Academic Writing. Nordic Journal of applied linguistics. 9 (2): 145-169

Nystrand, M. (1989). A Social Interactive Model of Writing. Written Communication, 6, 66-85.

Oliver, M. (2012) Technology and Change in Academic Practice. In Trowler et al. pp 220-231.

Rubio, M. (2011). A Pragmatic Approach to the Macro-Structure and Metadiscoursal Features of Research Article Introductions in the Field of Agricultural Sciences. English for Specific 
Purposes. 30 (4): 258-271

Salager-Meyer, F. (1999). Referential behavior in scientific writing: A diachronic study (1810-1995). English for Specific Purposes 18 (3): 279-305

Thompson, G. (2001) Interaction in academic writing: learning to argue with the reader. Applied Linguistics. 22 (1): 58-78.

Trowler, P., Saunders, M. \& Bamber, V. (eds.) (2012). Tribes and territories in the $21^{\text {st }}$ century. London: Routledge.

Tse, P. \& Hyland, K. (2006). 'So what is the problem this book addresses?' Interactions in book reviews. Text and Talk. Vol 27. 767-790.

Valle, E. (1999). A Collective Intelligence: The Life Sciences in the Royal Society as a Scientific Discourse Community, 1665-1965. University of Turku

Vande Kopple, W J. (1985). Some Exploratory Discourse on Metadiscourse. College Composition and Communication 26: 82-93.

\section{Appendix 1: Journal list}

\section{Applied Linguistics}

TESOL Quarterly (1967- )

Language Learning (1948- )

Foreign Language Annals (1967- )

Modern Language Journal (1916- )

College Composition and Communication (1950- )

\section{Sociology}

American Journal of Sociology (1895- )

Social problems (1953- )

The British Journal of Sociology (1950- )

American Journal of Economics and Sociology (1941- )

The Sociological Quarterly (1960- ) 


\section{Biology}

The Quarterly Review of Biology (1926- )

Biological Reviews (1923- )

Radiation Research (1954- )

BioScience (1964- )

The Journal of Experimental Biology (1923 - )

\section{Electrical Engineering}

Proceedings of the IEEE (1963 - )

Automatica (1963 - )

IEEE Transactions on Automatic Control (1963 - )

IEEE Journal of Solid-State Circuits (1966 - )

IEEE Transactions on Information Theory (1963 - ) 
Ken Hyland is Professor of Applied Linguistics in Education at the University of East Anglia where he has recently moved following several years at the University of Hong Kong. He has published over 220 articles and 27 books on academic discourse and EAP with over 34,000 citations on Google Scholar. A collection of his work was recently published as the Essential Hyland (Bloomsbury, 2018).

Feng (Kevin) Jiang is Kuang Yaming Distinguished Professor in applied linguistics in the School of Foreign Language Education at Jilin University, China and gained his $\mathrm{PhD}$ under the supervision of Professor Ken Hyland at the Centre for Applied English Studies at the University of Hong Kong. His research interests include disciplinary discourse, corpus studies and academic writing, and his publications have appeared in most major applied linguistics journals. 